\title{
The Frequency and Impact of Exposure to Potentially Traumatic Events Over the Life Course
}

Clinical Psychological Science XX(X) 1-9

(C) The Author(s) 2013

Reprints and permissions:

sagepub.com/journalsPermissions.nav DOI: $10.1177 / 2167702613485076$

cpx.sagepub.com

\author{
Christin M. Ogle ${ }^{1}$, David C. Rubin ${ }^{1,2}$, Dorthe Berntsen ${ }^{2}$, \\ and Ilene C. Siegler ${ }^{1,3}$ \\ ${ }^{1}$ Duke University, ${ }^{2}$ Aarhus University, and ${ }^{3}$ Duke University Medical Center
}

\begin{abstract}
We examined the frequency and impact of exposure to potentially traumatic events in a nonclinical sample of older adults $(N=3,575)$, a population typically underrepresented in epidemiological research concerning the prevalence of traumatic events. Current posttraumatic stress disorder (PTSD) symptom severity and the centrality of events to identity were assessed for events nominated as currently most distressing. Approximately $90 \%$ of participants experienced one or more potentially traumatic events. Events that occurred with greater frequency early in the life course were associated with more severe PTSD symptoms compared to events that occurred with greater frequency during later decades. Early life traumas, however, were not more central to identity. Results underscore the differential impact of traumatic events experienced throughout the life course. We conclude with suggestions for further research concerning mechanisms that promote the persistence of posttraumatic stress related to early life traumas and empirical evaluation of psychotherapeutic treatments for older adults with PTSD.
\end{abstract}

\section{Keywords}

lifetime trauma exposure, PTSD symptom severity, event centrality, older adulthood

Received 1/25/13; Revision accepted 3/8/13

Older adults are an ideal population within which to examine the prevalence and impact of exposure to traumatic events. They have lived long enough to potentially be exposed to many types of trauma, and in general they have the requisite cognitive functions to report their experiences. Furthermore, studies on older adults allow researchers to examine the persistence of symptoms associated with traumatic events experienced at different points throughout the life course. Despite these advantages, most studies concerning lifetime trauma exposure have examined young adults (e.g., Breslau, Davis, Andreski, \& Peterson, 1991), military veterans (e.g., Schnurr, Spiro, Vielhauer, Findler, \& Hamblen, 2002), or samples ranging broadly in age with older adults omitted (Kessler, Sonnega, Bromet, Hughes, \& Nelson, 1995). The generalizability of results from these studies to the prevalence of traumatic events over the life course is questionable given the increased likelihood of encountering a traumatic event with age (Creamer \&
Parslow, 2008; Glaesmer, Gunzelmann, Braehler, Forstmeier, \& Maercker, 2010) and the underestimation of events that occur with greater frequency later in life. The present study was designed to expand the limited knowledge concerning the prevalence and impact of lifetime trauma exposure among community-dwelling older adults and to advance our understanding of the extent to which the negative consequences of traumatic experiences from across the life course persist and cause distress during older adulthood.

Results from the few existing studies that included subsamples of community-dwelling older individuals indicate that most older adults experience at least one traumatic event during their lifetime (Norris, 1992) and that rates of

\footnotetext{
Corresponding Author:

Christin M. Ogle, Department of Psychology \& Neuroscience, Duke

University, Box 90086, Durham, NC 27708

E-mail: christin.ogle@duke.edu
} 
exposure among older adults can be higher than rates among younger individuals. For example, Spitzer et al. (2008) found that $76.5 \%$ of individuals aged 65 and older reported one or more traumatic life events, an approximate fourfold increase compared to the rate of exposure among the young adult and middle-aged participants. Studies concerning the consequences of trauma exposure further suggest that the severity of posttraumatic outcomes may depend on the nature and timing of the event. In one study that included subsamples of older adults from six European countries, the potentially traumatic events that were most strongly associated with posttraumatic stress disorder (PTSD) tended to be interpersonal in nature (e.g., rape, partner violence; Darves-Bornoz et al., 2008). Research on the impact of trauma as a function of age at exposure has produced more inconsistent findings, with some studies indicating that young adulthood and midlife traumatic events more strongly predict negative posttraumatic outcomes during older adulthood (Dulin \& Passmore, 2010; Krause, 2005) and other research showing that traumas experienced after age 50 are most consequential for late-life mental health (Shrira, Shmotkin, \& Litwin, 2012). Still other research indicates that the detrimental effects of trauma are greater for events encountered early in development (e.g., Colbert \& Krause, 2009).

The present study provides detailed information concerning when different types of traumas are likely to occur and the types of events that are most likely to cause distress during older adulthood. Such information is needed to clarify previous findings and to advance our understanding of factors that promote adverse posttraumatic outcomes among older adults. Research aimed at identifying the characteristics of traumatic events that contribute to distress among older adults may also inform clinical practice and ultimately improve treatment services for older individuals. Understanding the factors that contribute to poor psychological health and well-being in older adulthood is becoming critically important given demographic shifts that have resulted in older adults composing an increasingly disproportionate percentage of the population of the United States and other industrialized countries. In addition, the growing literature linking trauma exposure and PTSD to an elevated risk of aging-related disease (e.g., Kubzansky, Koenen, Spiro, Vokonas, \& Sparrow, 2007) further underscores the need for more research to inform clinical treatments for older adult survivors of trauma.

We tested a large nonclinical cohort of older adults to provide a clearer picture of when and with what frequency different kinds of events occur over the life course. PTSD symptom severity and the perceived centrality of the event to one's identity were assessed for the traumatic event that bothered participants most at the time of the study. A growing body of research indicates that greater centrality of a traumatic event to one's identity and life story is associated with negative posttraumatic outcomes including symptoms of PTSD and depression (Berntsen \& Rubin, 2006), reduced self-rated health (Boals, 2010), and lower self-esteem (Robinaugh \& McNally, 2011). In addition, the relative impact of different categories of traumatic events, including lifethreatening events, events that elicit strong emotional reactions, interpersonal events, and events that occur early versus later in the life course, was assessed to identify event characteristics that are associated with distress in older adulthood.

\section{Method}

\section{Participants}

Data were drawn from Wave 12 of the University of North Carolina Alumni Heart Study (UNCAHS), a longitudinal study of students who entered the University of North Carolina at Chapel Hill between 1964 and 1966 (Siegler et al., 1992). The recruitment procedures and participation rates of the UNCAHS are detailed elsewhere (Berntsen, Rubin, \& Siegler, 2011; Hooker, Hoppmann, \& Siegler, 2010). Because $97 \%(N=3,575)$ of Wave 12 respondents were 55 to 69 years of age, our analyses were limited to this group to provide a more uniform age range. Mean age was $60.73(S D=1.85)$. The sample was $67 \%$ male and $99.27 \%$ Caucasian, $0.40 \%$ African American, 0.08\% Hispanic, 0.08\% American Indian, and 0.06\% mixed race. An additional 4 participants (0.11\%) declined to identify their ethnicity. Approximately 9\% had less than a college degree, 19\% had bachelor's degrees, 26\% had bachelor's degrees plus additional training, 25\% had master's degrees, and $22 \%$ had doctorate or medical degrees. The median annual household income was in the $\$ 70,000$ to $\$ 99,999$ range.

\section{Measures}

Potentially traumatic events. The Traumatic Life Events Questionnaire (TLEQ; Kubany et al., 2000) was used to assess lifetime exposure to potentially traumatic events. Participants reported how often they experienced each of 19 types of events (Table 1) using a 7-point scale ( 0 = never, $6=$ more than 5 times $)$. For the most serious occurrence of each event type, participants reported their age at the event and indicated whether Criterion A2 of the fourth edition, text revision of the Diagnostic and Statistical Manual of Mental Disorders (DSM-IV-TR; American Psychiatric Association, 2000) was met. The TLEQ assesses a broader spectrum of events capable of producing PTSD symptoms compared to other trauma inventories and has strong psychometric properties and 
Table 1. Lifetime Prevalence of Potentially Traumatic Events as a Function of Age at Exposure by Decade

\begin{tabular}{|c|c|c|c|c|c|c|c|c|c|}
\hline \multirow[b]{2}{*}{ Event type } & \multicolumn{8}{|c|}{ Age at exposure } & \multirow[b]{2}{*}{ Total } \\
\hline & $M$ & $S D$ & $\leq 10$ & $\leq 20$ & $\leq 30$ & $\leq 40$ & $\leq 50$ & $\leq 60^{\mathrm{a}}$ & \\
\hline Childhood physical abuse & 9.51 & 3.74 & 110 & 65 & 0 & 0 & 0 & 0 & 175 \\
\hline Witnessed childhood family violence & 10.60 & 4.53 & 203 & 139 & 6 & 1 & 1 & 0 & 350 \\
\hline Sexual assault & 13.33 & 7.82 & 138 & 167 & 33 & 5 & 3 & 2 & 348 \\
\hline Warfare or combat exposure & 25.49 & 7.76 & 2 & 14 & 247 & 9 & 15 & 9 & 296 \\
\hline Physical assault by stranger & 26.87 & 12.81 & 7 & 69 & 64 & 21 & 12 & 18 & 191 \\
\hline Witnessed an attack or murder & 27.34 & 11.65 & 1 & 43 & 58 & 14 & 14 & 8 & 138 \\
\hline Nondisclosed & 28.01 & 16.52 & 19 & 29 & 30 & 17 & 9 & 20 & 124 \\
\hline Non-live birth pregnancy & 30.39 & 6.84 & 1 & 58 & 504 & 376 & 64 & 8 & 1,011 \\
\hline Motor vehicle accident & 30.67 & 14.93 & 28 & 189 & 167 & 81 & 87 & 96 & 648 \\
\hline Other life-threatening accident & 31.43 & 15.70 & 26 & 54 & 68 & 50 & 41 & 44 & 283 \\
\hline Other life-threatening event & 31.82 & 16.06 & 64 & 98 & 160 & 93 & 66 & 114 & 595 \\
\hline Death threat & 34.55 & 13.67 & 12 & 52 & 137 & 104 & 60 & 73 & 438 \\
\hline Stalked & 34.70 & 13.33 & 4 & 23 & 55 & 39 & 36 & 26 & 183 \\
\hline Robbery & 34.85 & 12.24 & 6 & 20 & 91 & 80 & 47 & 37 & 281 \\
\hline Physical assault by partner & 35.23 & 11.28 & 2 & 11 & 98 & 63 & 53 & 26 & 253 \\
\hline Natural disaster & 38.52 & 16.02 & 18 & 17 & 25 & 17 & 64 & 54 & 195 \\
\hline Unexpected death of a loved one & 39.41 & 14.55 & 26 & 188 & 324 & 303 & 376 & 493 & 1,710 \\
\hline Personal illness or accident & 43.98 & 16.71 & 48 & 30 & 45 & 57 & 106 & 304 & 590 \\
\hline Illness or accident of a loved one & 45.84 & 12.74 & 12 & 47 & 93 & 148 & 261 & 473 & 1,034 \\
\hline
\end{tabular}

Note: Events are presented in ascending order by mean age at exposure.

${ }^{a}$ To adjust for the number of participants who were not old enough to report on events that occurred at ages 56 through 60 , multiply frequencies in the $\leq 60$ column by 1.08 .

high convergent validity with structured clinical interviews (Kubany et al., 2000). Similar to epidemiological studies of trauma exposure that used mail surveys (e.g., Kessler et al., 1995), TLEQ items were modified to provide respondents extra privacy in reporting and to reduce redundancy. Details of the modifications are described elsewhere (Ogle, Rubin, \& Siegler, in press). Relevant to the present analyses, for each event type, participants were also asked whether or not the event met the DSM$I V$-TR A1 criterion (i.e., "Did the event involve actual or threatened death, serious injury, or threat to the physical integrity of yourself or others?”).

To examine the extent to which the impact of trauma exposure varied for different types of events, TLEQ items that were nominated by participants as currently most distressing were classified into several dichotomies. First, individual events were categorized as either life threatening or non-life-threatening according to whether or not the participant endorsed the A1 criterion. Second, individual events were classified as evoking a strong emotional response according to whether or not the participant endorsed the A2 criterion. Third, individual events were classified as interpersonal or non-interpersonal according to whether they involved intentional, personal assaultive acts or violations perpetrated by others (see the superscripts in Table 2). Finally, the mean age of occurrence and the distribution of events across the life span (Table 2) were used to classify events that occurred early in life versus those that occurred later. For an event to be categorized as an early event, the mean age of occurrence had to be less than 30 , and at least $80 \%$ of the events in the category were required to occur during the first three decades of life.

PTSD symptom severity. The PTSD Checklist-Stressor Specific Version (PCL-S; Weathers, Litz, Huska, \& Keane, 1994) is a 17-item PTSD screening instrument that yields a measure of symptom severity. Using 5-point scales ( 1 = not at all, $5=$ extremely), respondents indicate the extent to which a specific event produced each of the B, C, and D DSM-IV-TR PTSD symptoms during the previous month. The PCL has strong psychometric properties (Blanchard, Jones-Alexander, Buckley, \& Forneris, 1996) and high diagnostic agreement with the Clinician-Administered PTSD Scale ( $r=.93$; Blake et al., 1990).

Event centrality. The Centrality of Event Scale (CES; Berntsen \& Rubin, 2006) assesses the extent to which a trauma forms a central component of personal identity, a turning point in the life story, and a reference point for 
Table 2. Prevalence of Most Distressing Potentially Traumatic Events, Age at Exposure by Decade, PTSD Symptom Severity, and Event Centrality Scores

\begin{tabular}{|c|c|c|c|c|c|c|c|c|c|c|c|c|}
\hline \multirow[b]{2}{*}{ Event type } & \multicolumn{8}{|c|}{ Age at exposure } & \multicolumn{2}{|c|}{ PCL } & \multicolumn{2}{|c|}{ CES } \\
\hline & $M$ & $S D$ & $\leq 10$ & $\leq 20$ & $\leq 30$ & $\leq 40$ & $\leq 50$ & $\leq 60$ & $M$ & $S D$ & $M$ & $S D$ \\
\hline Childhood physical abuse $^{a}$ & 9.50 & 2.97 & 14 & 8 & 0 & 0 & 0 & 0 & 25.27 & 8.14 & 2.96 & 1.22 \\
\hline $\begin{array}{l}\text { Witnessed childhood } \\
\text { family violence }\end{array}$ & 10.54 & 4.07 & 47 & 33 & 0 & 1 & 0 & 0 & 25.21 & 11.76 & 2.64 & 1.16 \\
\hline Sexual assault ${ }^{\mathrm{a}}$ & 11.81 & 6.43 & 24 & 34 & 2 & 2 & 0 & 0 & 26.76 & 13.57 & 2.44 & 1.30 \\
\hline $\begin{array}{l}\text { Warfare or combat } \\
\text { exposure }^{\mathrm{a}}\end{array}$ & 25.08 & 7.96 & 1 & 5 & 76 & 1 & 3 & 4 & 27.12 & 13.70 & 2.93 & 1.19 \\
\hline Non-live birth pregnancy ${ }^{\mathrm{b}}$ & 31.01 & 6.96 & 0 & 4 & 50 & 37 & 7 & 1 & 19.44 & 3.96 & 1.90 & 0.94 \\
\hline $\begin{array}{l}\text { Physical assault by } \\
\text { stranger }^{\mathrm{a}}\end{array}$ & 33.22 & 15.98 & 0 & 6 & 8 & 2 & 1 & 6 & 22.70 & 9.46 & 1.68 & 1.06 \\
\hline Nondisclosed & 33.67 & 15.73 & 2 & 6 & 4 & 8 & 5 & 5 & 31.94 & 13.07 & 3.16 & 1.22 \\
\hline Life-threatening accident ${ }^{\mathrm{b}}$ & 33.77 & 13.33 & 0 & 5 & 14 & 14 & 3 & 8 & 22.09 & 7.04 & 2.31 & 1.10 \\
\hline Motor vehicle accident ${ }^{\mathrm{b}}$ & 34.94 & 14.90 & 3 & 24 & 29 & 21 & 18 & 28 & 21.30 & 6.40 & 1.95 & 1.11 \\
\hline $\begin{array}{l}\text { Other life-threatening } \\
\text { event }\end{array}$ & 36.97 & 17.17 & 10 & 13 & 22 & 17 & 11 & 39 & 24.74 & 10.06 & 2.56 & 1.28 \\
\hline Physical assault by partner ${ }^{\mathrm{a}}$ & 38.40 & 10.16 & 0 & 0 & 12 & 5 & 10 & 3 & 24.67 & 9.11 & 2.56 & 1.29 \\
\hline Death threat ${ }^{\mathrm{a}}$ & 39.35 & 15.56 & 0 & 3 & 6 & 4 & 4 & 10 & 21.04 & 6.86 & 1.84 & 0.91 \\
\hline $\begin{array}{l}\text { Witnessed attack or } \\
\text { murder }^{\mathrm{a}}\end{array}$ & 39.57 & 11.55 & 0 & 0 & 1 & 2 & 3 & 1 & 20.00 & 3.22 & 2.08 & 1.06 \\
\hline Stalked $^{\mathrm{a}}$ & 40.00 & 13.70 & 0 & 1 & 4 & 3 & 1 & 4 & 21.15 & 6.49 & 1.57 & 0.73 \\
\hline Robbery $^{a}$ & 40.88 & 12.21 & 0 & 1 & 6 & 12 & 5 & 10 & 20.19 & 7.99 & 1.77 & 0.99 \\
\hline $\begin{array}{l}\text { Unexpected death of a } \\
\text { loved one } \mathrm{e}^{\mathrm{b}}\end{array}$ & 40.92 & 14.36 & 9 & 63 & 118 & 118 & 152 & 231 & 21.79 & 7.99 & 2.51 & 1.19 \\
\hline Natural disaster ${ }^{\mathrm{b}}$ & 45.03 & 13.00 & 2 & 1 & 2 & 1 & 15 & 16 & 19.71 & 4.38 & 1.94 & 0.96 \\
\hline $\begin{array}{l}\text { Illness or accident of a } \\
\text { loved one } \mathrm{e}^{\mathrm{b}}\end{array}$ & 48.07 & 10.98 & 0 & 5 & 20 & 25 & 51 & 126 & 22.31 & 7.68 & 2.70 & 1.21 \\
\hline $\begin{array}{l}\text { Personal illness or } \\
\text { accident }^{\mathrm{b}}\end{array}$ & 48.57 & 12.80 & 7 & 5 & 11 & 18 & 48 & 132 & 23.85 & 7.70 & 3.20 & 1.19 \\
\hline
\end{tabular}

Note: $N=2,056$. CES $=$ Centrality of Event Scale; PCL $=$ PTSD Checklist. Events are presented in ascending order by mean age at exposure. Events without a superscript were not included in this classification because the nature of the event was unspecified.

${ }^{a}$ Interpersonal events.

${ }^{\mathrm{b}}$ Non-interpersonal events.

everyday inferences. Items are rated on 5-point scales $(1=$ totally disagree, $5=$ totally agree $)$. Mean scores are reported. Example items include "This event permanently changed my life" and "I feel this event has become part of my identity." The scale's reported reliability is .88 . Respondents completed the seven-item short version of the CES in reference to the TLEQ item that bothered them most at the time of the study.

\section{Procedure}

UNCAHS members first received instructions to complete the Wave 12 questionnaire online. Individuals who did not respond were mailed identical paper surveys up to three times. On the Wave 12 questionnaire, participants first answered questions concerning their health status, followed by the TLEQ. The CES and PCL were then completed in relation to the TLEQ event that currently bothered them most. All waves of the UNCAHS were approved by the Duke University Medical Center institutional review board.

\section{Data analysis}

Statistical significance was based on two-sided tests at the .05 level. To examine differences in PTSD symptom severity and event centrality for the dichotomous event categories, $t$ tests were conducted. The utility of each category in predicting PTSD symptom severity and event centrality was compared using multiple regression analysis. Age, education, gender, income, and marital status were entered in regression models as possible confounders. Standardized beta weights for the final model are presented. 


\section{Results}

\section{Prevalence of potentially traumatic events}

Approximately $90 \%$ of respondents $(n=3,208)$ reported exposure to one or more types of events $(M=2.85, S D=$ 2.16 , range $=0-13)$. The majority $(78.21 \%)$ of individuals with a history of at least one event reported exposure to two or more event types. When multiple occurrences of the same type of event were considered, the mean number of events was $5.31(S D=5.99$, range $=0-56)$.

To provide an overview of how often participants experienced each of the potentially traumatic events over the life course, Table 1 displays frequencies for lifetime exposure to the TLEQ events as a function of age at exposure split by decade. Although $53.37 \%$ of the sample was 60 years of age or older, only $5.71 \%$ was older than age 63, which precluded stable frequency estimates for events that occurred throughout the next decade. Therefore, data are presented for events that occurred at age 60 and younger for the 3,084 respondents who reported their age at exposure to TLEQ events. Prevalence rates were highest for unexpected death of a loved one. Illness or accident of a loved one and non-live birth pregnancy were also relatively common, with approximately one third of participants reporting exposure to each of these events. The age distribution of events revealed that some events such as sexual assaults occurred with greater frequency at younger ages, whereas other events (e.g., unexpected death of a loved one) were more prevalent after the transition to adulthood ( $\geq$ age 20). Similarly, illness or accident of a loved one and personal illness or accident occurred with greater frequency during later decades of the life course. Many low-frequency events, including natural disasters, were more uniformly distributed across the life span.

\section{Impact of potentially traumatic events}

Our second research question concerned differences in the impact of potentially traumatic events as a function of event type and age at exposure. Table 2 presents data from a subset of participants $(n=2,056)$ who nominated a TLEQ event that currently bothered them most and completed the PCL and the CES in reference to the event. As with Table 1, the age distribution of events in Table 2 includes those that occurred at age 60 and younger. The values for the PCL and CES include the full sample. PTSD symptom severity was greatest for nondisclosed events, followed by warfare or combat exposure. Event centrality was greatest for personal illness or accident, followed by nondisclosed events. Greater event centrality was strongly related to more severe PTSD symptoms $(r=.56, p<.001)$.
Events nominated by participants as currently most distressing were unequally distributed across the life course. Witnessed childhood family violence was the most frequent event to be nominated at age 10 or younger, whereas unexpected death of a loved one was the most common trauma to be nominated for ages 11 to 60 . Despite the high frequency of unexpected death of $a$ loved one, this event was associated with lower PTSD symptom severity compared to events that occurred primarily during childhood and adolescence ( $M$ age $<12$ ), $t(878)=5.23, p<.001$.

To further determine the nature of events that were associated with greater PTSD symptom severity and event centrality, TLEQ items were categorized into four dichotomies using key distinctions from the PTSD literature: (a) life-threatening versus non-life-threatening events, (b) events that evoked strong emotional reactions versus those that did not, (c) interpersonal versus non-interpersonal events, and (d) events that occurred early in life versus those that occurred later as indicated by mean age of occurrence. PTSD symptom severity was significantly higher for (a) life-threatening $(M=24.02, S D=9.78)$ compared to non-life-threatening events $(M=20.81$, $S D=6.50)$, (b) A2 $(M=25.02, S D=10.45)$ compared to non-A2 events $(M=20.61, S D=6.08)$, (c) interpersonal $(M=24.73, S D=11.45)$ compared to non-interpersonal events $(M=21.97, S D=7.53)$, and $(\mathrm{d})$ early life $(M=$ $26.27, S D=12.64)$ compared to later events $(M=22.32$, $S D=8.01), t s(1906-2054) \geq 5.73, p s \leq .001$. Event centrality scores were significantly higher for (a) life-threatening ( $M=2.82, S D=1.24)$ compared to non-life-threatening events $(M=2.11, S D=1.08)$, (b) A2 $(M=2.94, S D=1.24)$ compared to non-A2 events $(M=2.15, S D=1.09)$, and (c) early $(M=2.72, S D=1.22)$ compared to later events $(M=2.51, S D=1.22), t \mathrm{~s}(1973-2054) \geq 2.50, p s \leq .05$. No differences in event centrality emerged for interpersonal ( $M=2.45, S D=1.23)$ compared to non-interpersonal traumas $(M=2.55, S D=1.22)$. When warfare or combat exposure was classified as a later event, the relevant $t$ test remained significant.

Next, the relative utility of each of the four event categories in predicting PTSD symptom severity and event centrality was examined in a series of multiple regressions. In each model, sociodemographic variables were entered on the first step, followed by the event categories on Step 2. Because the interpersonal versus non-interpersonal and early versus later event dichotomies were highly correlated $(r=-.77)$, they were tested in separate regressions to avoid multicollinearity. Results indicated that all event categories significantly predicted PCL scores. Criterion A2 events were the strongest predictor of greater PTSD symptom severity ( $\beta=.17$ ), followed by early life events ( $\beta=-.13)$, interpersonal events $(\beta=.11)$, and criterion A1 events $(\beta=.09)$, final model including non-interpersonal 
versus interpersonal events, $F(8,1840)=25.32, p<.001, R^{2}$ $=.10$; final model including early versus later events, $F(8$, $1946)=28.60, p<.001, R^{2}=.11$. Criterion A2 events also emerged as the strongest predictor of event centrality ( $\beta$ $=.21$ ), followed by criterion A1 events $(\beta=.17)$. Although non-interpersonal events significantly predicted event centrality $(\beta=-.06)$, the magnitude of the standardized beta and the nonsignificant correlation $(r=-.03)$ between event centrality scores and interpersonal versus noninterpersonal events suggest that the contribution of noninterpersonal events to event centrality was small, final model, $F(8,1840)=41.26, p<.001, R^{2}=.15$. No association was found between the early versus later dichotomy and event centrality $(\beta=-.04)$, final model, $F(8,1946)=$ $42.95, p<.001, R^{2}=.15$.

\section{Discussion}

The present study examined the frequency and impact of exposure to potentially traumatic events as a function of age at exposure and event type in a nonclinical sample of older adults. Approximately $90 \%$ of participants reported exposure to one or more types of potentially traumatic events during their lifetime. Consistent with previous research (Kessler et al., 1995), more than half reported exposure to two or more event types. Although the rate of exposure in our study is higher than in previous research that examined the DSM-III-R definition of a trauma among samples ranging broadly in age (Kessler et al., 1995; Resnick, Kilpatrick, Dansky, Saunders, \& Best, 1993) as well as studies of non-North American samples (Creamer \& Parslow, 2008; Glaesmer et al., 2010), our results are comparable to the estimate of $89.6 \%$ reported in research in which $D S M-I V$ criteria were evaluated in a U.S. sample (Breslau et al., 1998).

Data concerning the timing of events indicated that certain types of traumas are more likely to occur during particular periods of the life course. Although, as expected, events such as warfare or combat exposure and non-live birth pregnancy were generally restricted to young adulthood, and childhood physical abuse was necessarily limited to childhood, the age-dependent nature of other events was more surprising. For example, sexual assaults were more than 13 times more likely to occur during the first decade of life compared to ages 31 to 60 , and the unexpected death of a loved one approximately doubled in frequency during each decade after the transition to adulthood.

Our findings also revealed that the severity of posttraumatic outcomes experienced in older adulthood varied by event type. Consistent with previous research by Darves-Bornoz and colleagues (2008), current PTSD symptom severity was highest for nondisclosed events, which suggests that shame and guilt may maintain the effects of trauma longer than other emotions. Nondisclosed events were also rated as closely central to personal identity, second to personal illnesses or accidents. When the impact of exposure to various categories of TLEQ events was tested in regression analyses, life-threatening events, events that evoked strong emotional reactions, and interpersonal events emerged as significant predictors of PTSD symptom severity. In addition, events that occurred with greater frequency early in life predicted greater PTSD symptom severity compared to events that were more prevalent later in life. This finding extends previous research concerning the impact of childhood adversity on outcomes measured in young adulthood and midlife (e.g., Goodman, Quas, \& Ogle, 2010; Kessler, Davis, \& Kendler, 1997) by demonstrating that the negative consequences of traumatic events encountered early in the life course persist into older adulthood. Early life traumas were also rated as more central to identity than later traumas, but this pattern did not hold in regression analyses with sociodemographic variables entered in the model. Likewise, the distinction between interpersonal and noninterpersonal events did not reliably predict event centrality.

The present findings add to our previous work concerning posttraumatic outcomes in older adults (Ogle et al., in press) by revealing when different types of traumatic events are likely to occur throughout the life course, as well as the types of traumas that are most likely to become integrated into one's identity and to cause distress during older adulthood. Our finding that the types of traumatic events that occur more frequently early in life are associated with greater PTSD symptom severity compared to more recent events underscores the need for future research to identify mechanisms underlying the persistence of posttraumatic stress associated with early traumas. One line of research in this area would involve examining possible differences in the narrative content and qualities of trauma memories from different periods of the life course. Investigating how objective (i.e., experimenter-rated properties) and subjective (i.e., participantrated phenomenological characteristics; Rubin, Dennis, \& Beckham, 2011) differences in early life versus recent trauma narratives relate to PTSD symptoms would increase our understanding of mechanisms involved in the development and maintenance of posttraumatic stress and inform various competing models of PTSD (e.g., Brewin, Dalgleish, \& Joseph, 1996; Ehlers \& Clark, 2000; Rubin, Berntsen, \& Bohni, 2008). Including older adults as well as cohorts of different ages would allow the time course of the differential effects of early life versus recent traumas to be analyzed. The study could be further expanded into a longitudinal-sequential design by retesting different age cohorts at intervals. This extension would allow longitudinal changes in the properties of 
early versus recent trauma memories to be compared and examined in relation to changes in symptom profiles over time. A longitudinal-sequential research design would also counteract cohort effects, which have limited the majority of previous longitudinal studies of trauma survivors.

Our findings also have implications for clinical practice. One question raised by our results is whether treatment outcomes for older adults with PTSD could be improved by therapeutic approaches that take into account the developmental timing of the trauma. Different therapies may be more effective at treating posttraumatic stress associated with early life compared to recent trauma exposure given that early traumas often entail losses and disruptions during a developmental stage characterized by numerous advances in social and cognitive processes (e.g., emotion regulation, attachment formation, autobiographical memory). Consistent with this idea, a growing number of studies have shown that severe trauma during childhood, especially experiences that are interpersonal in nature (e.g., prolonged childhood sexual abuse), can result in impairments and dysregulation in more diverse domains of functioning (e.g., affective, relational, identity) compared to similar traumas that occur later in the life cycle, such as adulthood sexual assault (e.g., Cloitre et al., 2009; van der Kolk, Roth, Pelcovitz, Sunday, \& Spinazzola, 2005). As a result, interventions that incorporate affect and interpersonal regulation skills training may be more effective at treating early life compared to recent traumas. Although promising results have been found for such treatments in studies of young and middle-aged adults with histories of childhood trauma (Cloitre et al., 2010; Ford, Courtois, Steele, van der Hart, \& Nijenhuis, 2005), well-controlled studies that test these protocols in older adults are needed to determine if such treatments are safe and effective for older individuals with histories of early life trauma. In contrast, cognitive-behavioral therapy might be more effective at treating PTSD related to recent traumatic experiences in older adulthood, which our results indicate are likely to be more punctuated events that cause changes in self-identity. However, limited data are available to aid clinicians in determining best treatment practices for older individuals with PTSD. To date, no randomized controlled trials (RCTs) have examined the efficacy of PTSD treatments specifically for older adults, nor have studies compared treatment efficacy for different kinds of traumas. Clinical guidelines concerning best practices for treating PTSD in older adults would be informed substantially by RCTs that evaluate the efficacy of treatment protocols designed for PTSD related to early life trauma and cognitive-behavioral therapies that have been empirically validated with young adult and middleaged populations (e.g., prolonged exposure, cognitive processing therapy).
Our results should be interpreted in the context of several limitations. First, because the UNCAHS is primarily composed of undergraduates who were in college during the 1960s, the sample is not representative of the general population with respect to education, gender, or ethnicity. Despite the underrepresentation of females and individuals with low education, both of which are risk factors for PTSD (Breslau et al., 1998; Kessler et al., 1995), our results indicate that trauma exposure and posttraumatic stress were not uncommon, even among welleducated older adults for whom support resources (e.g., financial, interpersonal) may be more available. Second, as with all cross-sectional analyses, the causal relation between lifetime trauma exposure and current PTSD symptom severity and event centrality cannot be determined and may have been caused by shared factors that were not examined in this study. Third, although the PCL is a reliable and valid measure of PTSD symptom severity (e.g., Blanchard et al., 1996), clinical interviews may be necessary to identify which cases of elevated PTSD symptom severity met criteria for diagnosis. Fourth, our findings may be subject to bias resulting from potential memory errors related to retrospective reports and defensive reporting due to the perceived stigma of certain events (e.g., childhood sexual abuse, rape). Finally, similar to epidemiological studies of PTSD (e.g., Kessler et al., 1995), PTSD symptoms were assessed for only one event per participant, which may have led to an underestimation of symptoms. Despite these limitations, our findings demonstrate that distress experienced in older adulthood can be traced to traumatic events endured decades earlier. Moreover, exposure to particular types of traumatic events, specifically those that are life threatening, events that elicit strong emotional reactions, traumas that are interpersonal in nature, and traumas that occur early in life, may be especially consequential for psychological health during older adulthood.

\section{Declaration of Conflicting Interests}

The authors declared that they had no conflicts of interest with respect to their authorship or the publication of this article.

\section{Funding}

This work was supported by the National Institute on Aging (Grant 5T32 AG000029-35), the National Heart Lung and Blood Institute (Grant P01-HL36587), the National Institute of Mental Health (Grant R01-MH066079), the Duke Behavioral Medicine Research Center, and the Danish National Research Foundation (Grant DNRF93).

\section{References}

American Psychiatric Association. (2000). Diagnostic and statistical manual of mental disorders (4th ed., text revision). Washington, DC: Author. 
Berntsen, D., \& Rubin, D. C. (2006). The Centrality of Event Scale: A measure of integrating a trauma into one's identity and its relation to post-traumatic stress disorder symptoms. Behaviour Research and Therapy, 44, 219-231.

Berntsen, D., Rubin, D. C., \& Siegler, I. C. (2011). Two versions of life: Emotionally negative and positive life events have different roles in the organization of life story and identity. Emotion, 11, 1190-1201.

Blake, D., Weathers, F., Nagy, L., Kaloupek, D., Klauminzer, G., Charney, D., \& Keane, T. (1990). Clinician-Administered PTSD Scale. Boston, MA: Boston VA, National Center for Post-Traumatic Stress Disorder, Behavioral Science Division.

Blanchard, E. B., Jones-Alexander, J., Buckley, T. C., \& Forneris, C. A. (1996). Psychometric properties of the PTSD Checklist (PCL). Behaviour Research and Therapy, 34, 669-673.

Boals, A. (2010). Autobiographical memories that have become central to identity: Gender differences in the Centrality of Events Scale for positive and negative events. Applied Cognitive Psychology, 24, 107-121.

Breslau, N., Davis, G. C., Andreski, P., \& Peterson, E. L. (1991). Traumatic events and posttraumatic stress disorder in an urban population of young adults. Archives of General Psychiatry, 48, 216-222.

Breslau, N., Kessler, R. C., Chilcoat, H. D., Schultz, L. R., Davis, G. C., \& Andreski, P. (1998). Trauma and posttraumatic stress disorder in the community: The 1996 Detroit Area Survey of Trauma. Archives of General Psychiatry, 55, 626-632.

Brewin, C. R., Dalgleish, T., \& Joseph, S. (1996). A dual representation theory of posttraumatic stress disorder. Psychological Review, 103, 670-686.

Cloitre, M., Stolbach, B. C., Herman, J. L., van der Kolk, B., Pynoos, R., Wang, J., \& Petkova, E. (2009). A developmental approach to complex PTSD: Childhood and adult cumulative trauma as predictors of symptom complexity. Journal of Traumatic Stress, 22, 399-408.

Cloitre, M., Stovall-McClough, K. C., Nooner, K., Zorbas, P., Cherry, S., Jackson, C. L., . . . Petkova, E. (2010). Treatment for PTSD related to childhood abuse: A randomized controlled trial. American Journal of Psychiatry, 167, 915-924.

Colbert, J. S., \& Krause, N. (2009). Witnessing violence across the life course, depressive symptoms, and alcohol use among older persons. Health Education E Behavior, 36, 259-277.

Creamer, M., \& Parslow, R. (2008). Trauma exposure and posttraumatic stress disorder in the elderly: A community prevalence study. American Journal of Geriatric Psychiatry, 16, 853-856.

Darves-Bornoz, J., Alonso, J., Girolamo, G., Graaf, R., Masfety, V., Lepine, J., . . . Gasquet, I. (2008). Main traumatic events in Europe: PTSD in the European study of the Epidemiology of Mental Disorders Survey. Journal of Traumatic Stress, 21, 455-462.

Dulin, P. L., \& Passmore, T. (2010). Avoidance of potentially traumatic stimuli mediates the relationship between accumulated lifetime trauma and late-life depression and anxiety. Journal of Traumatic Stress, 23, 296-299.

Ehlers, A., \& Clark, D. M. (2000). A cognitive model of posttraumatic stress disorder. Behaviour Research and Therapy, $38,319-345$.
Ford, J. D., Courtois, C. A., Steele, K., van der Hart, O., \& Nijenhuis, E. R. S. (2005). Treatment of complex posttraumatic self-dysregulation. Journal of Traumatic Stress, 18, 437-447.

Glaesmer, H., Gunzelmann, T., Braehler, E., Forstmeier, S., \& Maercker, A. (2010). Traumatic experiences and posttraumatic stress disorder among elderly Germans: Results of a representative population-based survey. International Psychogeriatrics, 22, 661-670.

Goodman, G. S., Quas, J. A., \& Ogle, C. M. (2010). Child maltreatment and memory. Annual Review of Psychology, 61, 325-351.

Hooker, K., Hoppmann, C., \& Siegler, I. C. (2010). Personality: Life span compass for health. Annual Review of Gerontology and Geriatrics, 30, 201-232.

Kessler, R. C., Davis, C. G., \& Kendler, K. S. (1997). Childhood adversity and adult psychiatric disorder in the US National Comorbidity Survey. Psychological Medicine, 27, 11011119 .

Kessler, R. C., Sonnega, A., Bromet, E., Hughes, M., \& Nelson, C. B. (1995). Posttraumatic stress disorder in the National Comorbidity Survey. Archives of General Psychiatry, 52, 1048-1060.

Krause, N. (2005). Traumatic events and meaning in life: Exploring variations in three age cohorts. Aging \& Society, 25, 501-524.

Kubany, E. S., Leisen, M. B., Kaplan, A. S., Watson, S. B., Haynes, S. N., Owens, J. A., \& Burns, K. (2000). Development and preliminary validation of a brief broad-spectrum measure of trauma exposure: The Traumatic Life Events Questionnaire. Psychological Assessment, 12, 210-224.

Kubzansky, L. D., Koenen, K. C., Spiro, A., Vokonas, P. S., \& Sparrow, D. (2007). Perspective study of posttraumatic stress disorder symptoms and coronary heart disease in the normative aging study. Archives of General Psychiatry, 64, 109-116.

Norris, F. H. (1992). Epidemiology of trauma: Frequency and impact of different potentially traumatic events on different demographic groups. Journal of Consulting and Clinical Psychology, 60, 409-418.

Ogle, C. M., Rubin, D. C., \& Siegler, I. C. (in press). The impact of the developmental timing of trauma exposure on PTSD symptoms and psychosocial functioning among older adults. Developmental Psychology.

Resnick, H. S., Kilpatrick, D. G., Dansky, B. S., Saunders, B., \& Best, C. L. (1993). Prevalence of civilian trauma and posttraumatic stress disorder in a representative national sample of women. Journal of Consulting and Clinical Psychology, 61, 984-991.

Robinaugh, D. J., \& McNally, R. J. (2011). Trauma centrality and PTSD symptom severity in adult survivors of childhood sexual abuse. Journal of Traumatic Stress, 24, 483-496.

Rubin, D. C., Berntsen, D., \& Bohni, M. K. (2008). A memorybased model of posttraumatic stress disorder: Evaluating basic assumptions underlying the PTSD diagnosis. Psychological Review, 115, 985-1011.

Rubin, D. C., Dennis, M. F., \& Beckham, J. C. (2011). Autobiographical memory for stressful events: The role of 
autobiographical memory in posttraumatic stress disorder. Consciousness and Cognition, 20, 840-856.

Schnurr, P. P., Spiro, A., Vielhauer, M. J., Findler, M. N., \& Hamblen, J. L. (2002). Trauma in the lives of older men: Findings from the normative aging study. Journal of Clinical Geropsychology, 8, 175-187.

Shrira, A., Shmotkin, D., \& Litwin, H. (2012). Potentially traumatic events at different points in the life span and mental health: Findings from SHARE-Israel. American Journal of Orthopsychiatry, 82, 251-259.

Siegler, I. C., Peterson, B. L., Barefoot, J. C., Harvin, S. H., Dahlstrom, W. G., Kaplan, B. H., . . Williams, R. B. (1992). Using college alumni populations in epidemiologic research: The UNC Alumni Heart Study. Journal of Clinical Epidemiology, 45, 1243-1250.

Spitzer, C., Barnow, S., Volzke, H., John, U., Freyberger, H. J., \& Grabe, H. J. (2008). Trauma and posttraumatic stress disorder in the elderly: Findings from a German community study. Journal of Clinical Psychiatry, 69, 693-700.

van der Kolk, B. A., Roth, S., Pelcovitz, D., Sunday, S., \& Spinazzola, J. (2005). Disorders of extreme stress: The empirical foundation of a complex adaptation to trauma. Journal of Traumatic Stress, 18, 389-399.

Weathers, F. W., Litz, B. T., Huska, J. A., \& Keane, T. M. (1994). The PTSD Checklist (PCL) (Unpublished scale). Available from the National Center for PTSD, Washington, DC. 